\title{
Button batteries in the oesophagus: A surgical emergency
}

\author{
K Milford, ${ }^{1} \mathrm{MB}$ ChB; A Numanoglu, ${ }^{1} \mathrm{MB}$ ChB, FCS; A Brooks, ${ }^{2}$ FC Cardio (SA); S Cox, ${ }^{1}$ MB ChB, FCS, Cert Paed Surg \\ ${ }^{1}$ Division of Paediatric Surgery, Red Cross War Memorial Children's Hospital and Faculty of Health Sciences, University of Cape Town, \\ South Africa \\ ${ }^{2}$ Christiaan Barnard Division of Cardiothoracic Surgery, Red Cross War Memorial Children's Hospital and Faculty of Health Sciences, \\ University of Cape Town, South Africa
}

Corresponding author: K Milford (karenmilford@gmail.com)

\begin{abstract}
We describe two cases of missed battery ingestion that led to extensive morbidity, requiring surgical management that would not have been necessary had the batteries been removed timeously.
\end{abstract}

S Afr Med J 2016;106(10):978-980. DOI:10.7196/SAMJ.2016.v106i10.11172

Small children frequently ingest foreign bodies. ${ }^{[1]}$ The true incidence of this is unknown, and most foreign bodies will pass through the gastrointestinal tract unnoticed and without causing any harm. ${ }^{[2]}$ Large or unusually shaped objects, however, may become lodged in the oesophagus and require endoscopic removal or advancement into the stomach. Button batteries need to be dealt with particularly urgently as they cause complications that can lead to extensive morbidity and even mortality. We describe two cases of missed battery ingestion seen in Cape Town, South Africa, that led to extensive morbidity, requiring surgical management that would not have been necessary had the batteries been removed timeously.

\section{Case 1}

A previously well 11-month-old boy was brought to a local facility with symptoms of a lower respiratory tract infection (tachypnoea, coughing and fever). A chest radiograph demonstrated a circular foreign body at the level of the cricopharyngeus muscle. Endoscopy was performed and a button battery was removed. Sloughing and necrosis

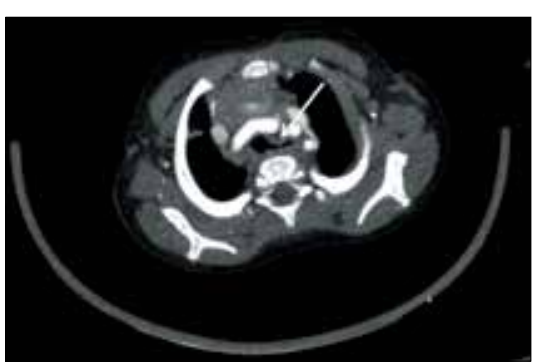

Fig. 1. CT cross-section through chest of patient 1, demonstrating tracheo-oesophageal fistula (arrow). of the oesophageal mucosa was noted at the time of endoscopy. Four days later, when the patient's symptoms had not settled, he underwent a computed tomography (CT) scan of the chest, which demonstrated a tracheo-oesophageal fistula (Fig. 1). At this point he was referred to Red Cross War Memorial Children's Hospital (RCWMCH), Cape Town.

At RCWMCH, he initially underwent defunctioning oesophagostomy, Nissen fundoplication and placement of a gastrostomy tube. Three weeks later he was taken for rightsided thoracotomy and underwent repair of the fistula; the oesophageal defect was sutured and an intercostal flap placed over the tracheal defect. Six weeks after this his oesophagostomy was reversed. He required dilatations of

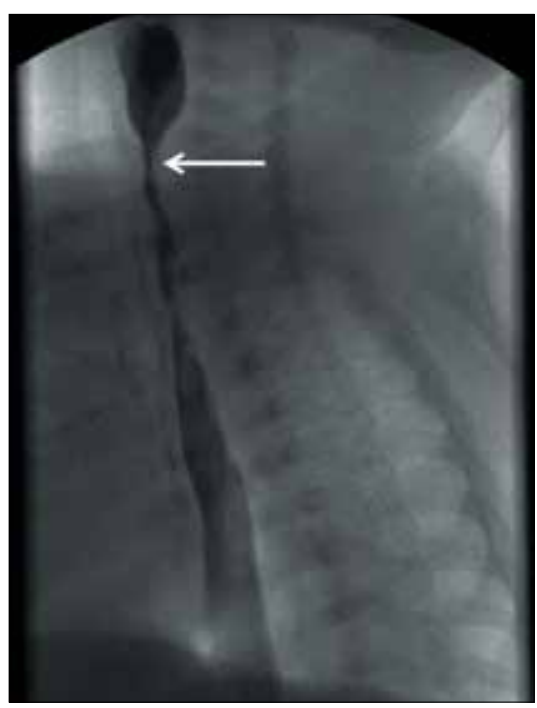

Fig. 2. Contrast swallow demonstrating stricture at level of previous defunctioning oesophagostomy (arrow), requiring dilatation. the oesophagostomy site for $\sim 7$ months (Fig. 2). $\mathrm{He}$ is now symptom free and growing well.

\section{Case 2}

A 6-year-old girl was taken to a general practitioner after swallowing a watch battery. The family was told that as long as she was passing stool normally, the battery would pass and that they need not worry about it. A year later she presented again with dysphagia and symptoms of aspiration (coughing after feeds and recurrent respiratory tract infections). A chest radiograph revealed a foreign body in the oesophagus (Fig. 3). The oesophagus

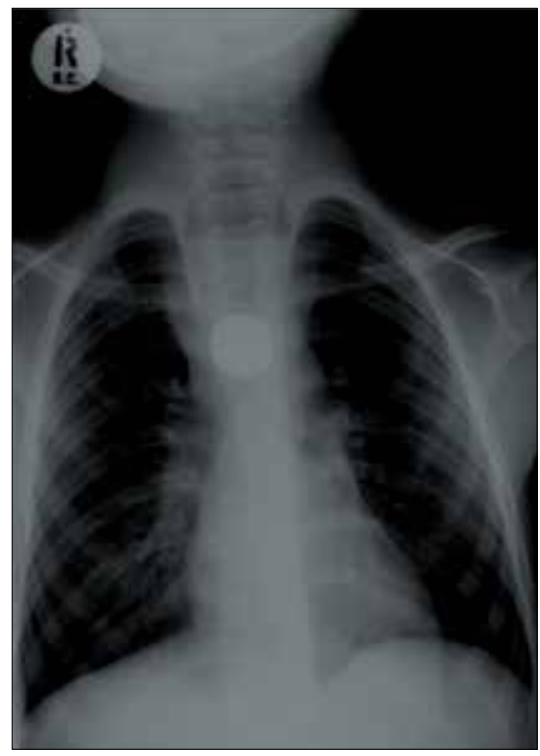

Fig. 3. Chest radiograph demonstrating button battery in the oesophagus of patient 2. Note the dilated proximal oesophagus containing an air/ fluid level, and the 'halo' sign indicating that this object is probably a battery, not a coin. 
proximal to this was dilated and had an air/ fluid level, and the lung fields showed features suggestive of aspiration pneumonia. A CT scan revealed a foreign body lodged posterior to the oesophagus and medial to the arch of the aorta (Figs 4 and 5).

The patient was taken to theatre, where oesophagoscopy revealed a tight oesophageal stricture but no visible foreign body. She then underwent thoracotomy and an inflammatory oesophageal stricture was identified, containing an alkali button battery. The stricture was resected and a primary oesophageal anastomosis was performed (Fig. 6). The patient is now eating well and gaining weight.

\section{Pathology}

Button batteries are small, disc-shaped batteries, commonly used to power small electronic devices such as wrist watches, clocks, calculators, kitchen scales and some toys.

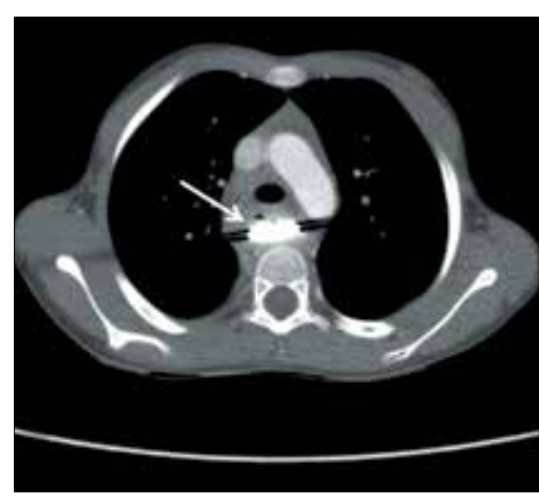

Fig. 4. CT cross-section through chest of patient 2, demonstrating a foreign body posterior to the oesophagus and medial to the aortic arch (arrow).

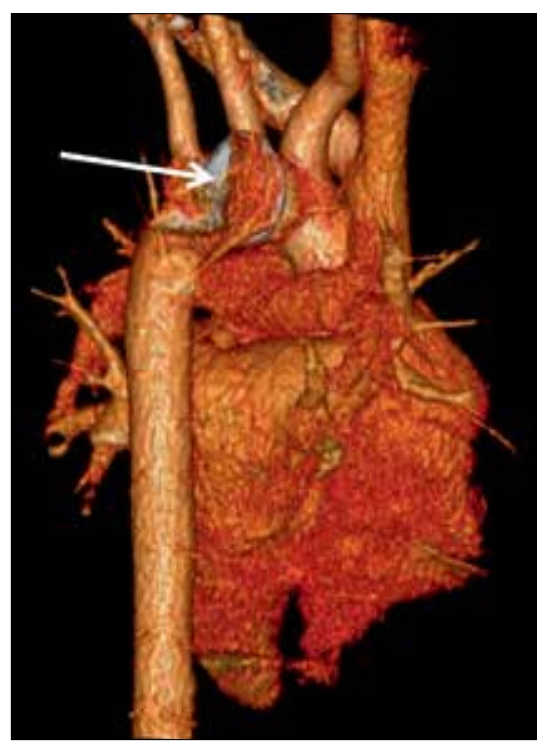

Fig. 5. 3D reconstruction of CT images demonstrating relationship of button battery to aortic arch (arrow) in patient 2.
They are typically $5-25 \mathrm{~mm}$ in diameter and $1-6 \mathrm{~mm}$ high. A button battery is a singlecell unit, with one half-cell being the cathode, or positive electrode, and the other half being the anode, or negative electrode. Anodes are commonly composed of metals such as zinc or lithium, and cathodes are commonly composed of substances such as manganese dioxide, silver oxide, carbon monofluoride, cupric oxide or oxygen. The anode and cathode are separated by an electrolyte, which allows the flow of electric charge between the two. ${ }^{[3]}$ In alkaline batteries, this electrolyte is potassium hydroxide.

Typically, batteries that become lodged in the oesophagus are $20 \mathrm{~mm}$ or more in diameter. ${ }^{[4-6]}$ Once the battery is in the restricted space of the oesophagus and in contact with its endothelium, which creates a circuit, it rapidly starts heating up, causing thermal cell damage. In addition, the casing erodes and leaks metals and hydroxide

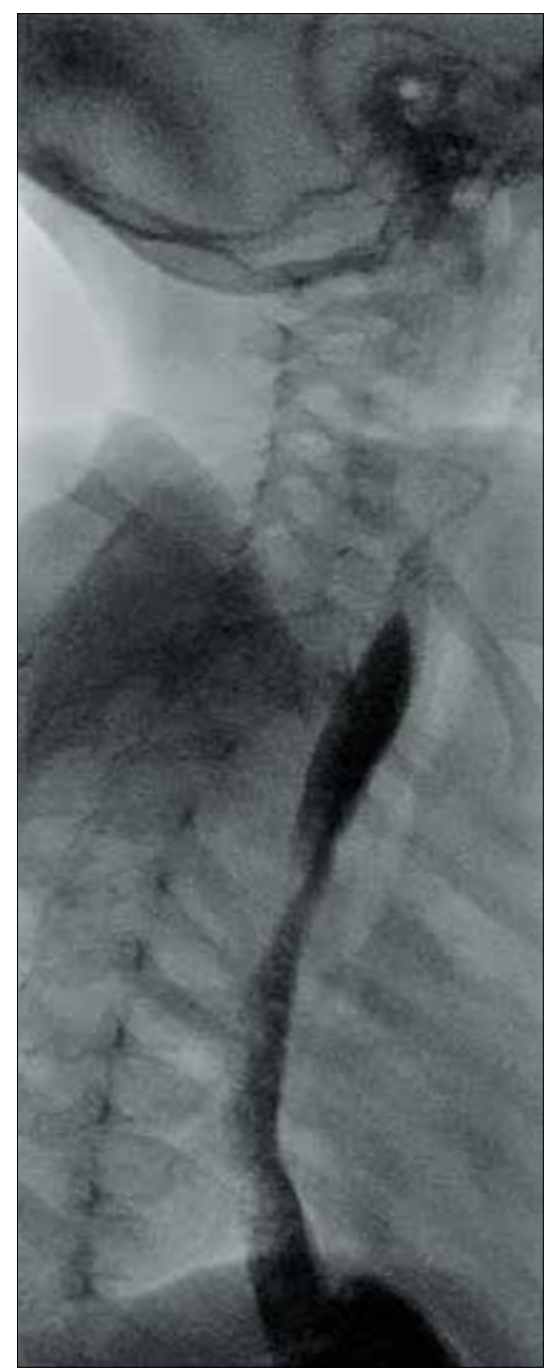

Fig. 6. Postoperative contrast swallow showing oesophagus after resection of stricture and primary oesophageal anastomosis in patient 2. anions. This causes an increase in $\mathrm{pH}$ with resulting liquefactive necrosis, as well as cytotoxic damage. All these changes can occur within 2 hours of ingestion. ${ }^{[7]}$

The complications of this damage to the oesophageal wall are serious. Oesophageal perforation can occur, ${ }^{[8]}$ and the battery can then go on to erode into surrounding structures. The literature describes a wide range of complications, including aortooesophageal fistula, ${ }^{[9,10]}$ which commonly presents as a herald bleed followed by a fatal upper gastrointestinal bleed, bilateral vocal cord paralysis, ${ }^{[9]}$ tracheo-oesophageal fistula, ${ }^{[11]}$ commonly presenting as aspiration pneumonia, oesophageal necrosis ${ }^{[6]}$ and oesophageal stenosis. ${ }^{[5,6]}$

\section{Diagnosis and investigation}

All children who present with a history of possible button battery ingestion should be investigated. The ingestion may be selfreported or witnessed by a caregiver. A plain anteroposterior chest radiograph will either confirm the presence of a button battery lodged in the oesophagus, or reassure the clinician and family that the battery has passed beyond the oesophagus and into the gastrointestinal tract. When a foreign body is confirmed to be lodged in the vicinity of the mediastinum, a lateral chest radiograph is useful in that it will help to determine the position in the mediastinum ${ }^{[12]}$ and also provide more information as to the nature of the object. ${ }^{[13]}$ In many cases, button battery ingestion may occur unnoticed, and children may be investigated after presenting with the symptoms of complications. These include abdominal pain, ${ }^{[6,9,14]}$ respiratory symptoms such as distress and tachypnoea, ${ }^{[6]}$ coughing, ${ }^{[9]}$ wheezing or stridor, ${ }^{[10,13]}$ and symptoms of oesophageal obstruction such as dysphagia, drooling ${ }^{[5,9]}$ and vomiting. ${ }^{[2]}$ Particularly ominous is a history of haematemesis. $^{[10]}$

In the case of oesophageal impaction, a chest radiograph will reveal a smooth, round object, most commonly lodged in the cricopharyngeal area, in the middle third of the oesophagus where the left main bronchus crosses the oesophagus (as this is anatomically the most narrow part of the oesophagus) or at the lower oesophageal sphincter. $^{[2]}$ The most commonly ingested foreign body is a coin, ${ }^{[1,2,13,14]}$ and if the ingestion went unwitnessed the battery may be mistaken for a coin on a plain radiograph. ${ }^{[12,13]}$ Clues that one may be dealing with a button battery rather than a coin may be found on the lateral film, where one side of the battery is perfectly flat while the 
other is convex, ${ }^{[13]}$ and one may see the 'step-off' sign, which refers to the 'step' between the battery and its casing. ${ }^{[1]}$ In addition, on a well-exposed film there is a rim of lucency on the inside edge of the battery, ${ }^{[13]}$ also known as the 'halo' sign (Fig. 3). ${ }^{[11]}$

The chest radiograph may also reveal features of complications of ingestion, such as pneumothorax and pneumomediastinum, ${ }^{[4,8,13]}$ lung field infiltrates ${ }^{[9]}$ and proximal oesophageal dilatation, as described in case 2 above. If there is evidence of complications, there may be value in doing further studies such as a contrast swallow examination ${ }^{[8]}$ or a CT scan.

\section{Management}

Because oesophageal button batteries cause local damage so rapidly, they must be removed as a matter of urgency. The practice at RCWMCH is to take children with an acute history and no radiographic features of complications to theatre urgently, and to remove the battery endoscopically under general anaesthesia. This approach is supported by the literature. ${ }^{[6,9,10,14]}$ At the time of endoscopy, the oesophagus is assessed for evidence of injury (mucosal burns, necrosis or perforation), and further management is based on these findings. In the case of children who present with radiographic evidence of complications or who are severely ill, the child is stabilised from a respiratory and haemodynamic point of view, and then further imaging is undertaken before formulating a surgical plan. This usually requires a right thoracotomy, with repair of the injured structures.

Button batteries that have passed beyond the oesophagus can be monitored, as they usually pass through the gastrointestinal tract spontaneously. ${ }^{[2]}$ If they remain in the stomach for $>48$ hours, endoscopy should be performed to remove them..$^{[2,15]}$

\section{Conclusion}

Button battery ingestion is common, and is associated with serious morbidity and possible mortality. Any child with a history of button battery ingestion should be investigated with a chest radiograph, and any patient with a foreign body impacted in the oesophagus should be referred to an appropriate centre for urgent endoscopic retrieval.

1. Van As AB, Du Toit N, Wallis L, Stool D, Chen X, Rode H. The South African experience with ingestion injury in children. Int J Pediatr Otorhinolaryngol 2003;67(Suppl. 1):175-178. DOI:10.1016/j.ijporl.2003.08.021

2. Uyemura MC. Foreign body ingestion in children. Am Fam Physician 2005;72(2):287-291, DOI:10.1016/j.arcped.2011.05.007

3. MIT School of Engineering. How does a battery work? http://engineering.mit.edu/ask/how-doesbattery-work (accessed 27 May 2016).

4. Marom T, Goldfarb A, Russo E, Roth Y. Battery ingestion in children. Int J Pediatr Otorhinolaryngol 2010;74(8):849-854. DOI:10.1016/j.ijporl.2010.05.019

5. Litovitz T, Schmitz BF. Ingestion of cylindrical and button batteries: An analysis of 2382 cases. Litovitz T, Schmitz BF. Ingestion
Pediatrics 1992;89(4 Pt 2):747-757.

6. Yardeni D, Yardeni H, Coran AG, Golladay ES. Severe esophageal damage due to button battery Yardeni D, Yardeni H, Coran AG, Golladay ES. Severe esophageal damage due to button battery
ingestion: Can it be prevented? Pediatr Surg Int 2004;20(7):496-501. DOI:10.1007/s00383-004-1223-6 ingestion: Can it be prevented? Pediatr Surg Int 2004;20(7):496-501. DOI:10.1007/s00383-004-1223-6
7. Chevin JC, Attik G, Dika H, et al. Button battery induced cell damage: A pathophysiological study. Electrochem Commun 2008;10(11):1756-1760. DOI:10.1016/.elecom.2008.09.002

8. Samad L, Ali M, Ramzi H. Button battery ingestion: Hazards of esophageal impaction. J Pediatr Surg 1999;34(10):1527-1531. DOI:10.1016/S0022-3468(99)90119-7

9. Hamilton JM, Schraff SA, Notrica DM. Severe injuries from coin cell battery ingestions: 2 case reports J Pediatr Surg 2009;44(3):644-647. DOI:10.1016/j.jpedsurg.2008.10.110

10. Mortensen A, Hansen NF, Schiødt OM. Fatal aortoesophageal fistula caused by button battery ingestion in a 1-year-old child. Am J Emerg Med 2010;28(8):984.e5-984.e6. DOI:10.1016/j.ajem.2010.01.007

11. Grisel JJ, Richter GT, Casper KA, Thompson DM. Acquired tracheoesophageal fistula following disc-battery ingestion: Can we watch and wait? Int J Pediatr Otorhinolaryngol 2008;72(5):699-706. DOI:10.1016/j.jpporl.2008.01.015

12. George AP, Alaani A, Carlin WV. The difficulty identifying unknown swallowed foreign bodies on plain X-ray. Int J Pediatr Otorhinolaryngol Extra 2008;3(1):1-2. DOI:10.1016/j.pedex.2007.06.004

13. Lee SC, Ebert CS, Fordham L, Rose AS. Plain films in the evaluation of batteries as esophageal foreign

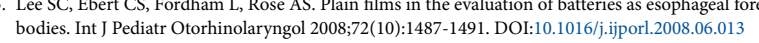

14. Timmers M, Snoek KG, Gregori D, Felix JF, van Dijk M, van As SA. Foreign bodies in a pediatric emergency department in South Africa. Pediatr Emerg Care 2012;28(12):1348-1352. DOI:10.1097/PEC.0b013e318276c20e

15. Lee JH, Lee JH, Shim JO, Lee JH, Eun BL, Yoo KH. Foreign body ingestion in children: Should button batteries in the stomach be urgently removed? Pediatr Gastroenterol Hepatol Nutr 2016;19(1):20-28. DOI:10.5223/pghn.2016.19.1.20

Accepted 20 June 2016 